\title{
Male recombination in Brazilian populations of Drosophila ananassae
}

\begin{tabular}{|r|l|}
\hline Journal: & Genome \\
\hline Manuscript ID & gen-2015-0169.R1 \\
\hline Manuscript Type: & Article \\
\hline Date Submitted by the Author: & 31 -Mar-2016 \\
\hline Complete List of Authors: & $\begin{array}{l}\text { Goñi, Beatriz; Universidad de la Republica, Facultad de Ciencias, Genética } \\
\text { Evolutiva } \\
\text { Matsuda, M.; Kyorin University, Biology } \\
\text { Tobari, Y.; The Research Institute of Evolutionary Biology }\end{array}$ \\
\hline Keyword: & $\begin{array}{l}\text { isofemale lines, genetic recombination, genetic variability, male crossing } \\
\text { over, natural populations }\end{array}$ \\
\hline
\end{tabular}




\section{Male recombination in Brazilian populations of Drosophila ananassae}

Beatriz Goñi, Muneo Matsuda, and Yoshiko N. Tobari

B. Goñi* and Yoshiko N. Tobari†. Department of Biology, Tokyo Metropolitan University, 1-1 Minami-Ohsawa, Hachioji, Tokyo 192-0397, Japan

M. Matsuda. Department of Biology, School of Medicine, Kyorin University, 6-20-2, Shinkawa, Mitaka, Tokyo 181-8611, Japan. (matsudam@ks.kyorin-u.ac.jp).

*Present address: Sección Genética Evolutiva, Instituto de Biología, Facultad de Ciencias, Universidad de la República, Iguá 4225, 11400 Montevideo, Uruguay. (bgoni@fcien.edu.uy).

$†$ Present address: The Research Institute of Evolutionary Biology, 2-4-28 Kamiyoga, Setagaya, Tokyo 158-0098, Japan (yntobari@yahoo.co.jp).

Corresponding author: B. Goñi (bgoni@fcien.edu.uy) Sección Genética Evolutiva, Instituto de Biología, Facultad de Ciencias, Universidad de la República, Iguá 4225, 11400 Montevideo, Uruguay. Phone: + 598-2525 8618 ext. 7141, Fax: + 598-2525 8617 
bstract: With few exceptions, spontaneous crossing over does not normally occur in male Drosophila. Drosophila ananassae males show considerable amounts of crossing over. In wild males of D. ananassae from Asian (2008) and Brazilian populations (1986 and 2007) variable frequencies of meiotic crossing over, estimated from chiasmata counts, suggested the existence of factors controlling male crossing over in these populations. To corroborate for such prediction, we present data on spontaneous recombination in $\mathrm{F}_{1}$ males of $D$. ananassae heterozygous for chromosomes of the same Brazilian populations (1986) and marker chromosomes using three testers stocks. Mean recombination value was low although high variability existed between individual frequencies. Recombination frequencies between lines in each tester stock were not significantly different, excepting when the 3ple-px and 3ple-cy testers were compared $(p<0.05)$. These two testers differ respect to the regional distribution of crossovers. The occurrence of recombination in chromosomes 2 and 3 in $\mathrm{F}_{1}$ males tested with $e^{65} s e$; bri $r u$ was not related, suggesting they are under independent genetic control. Our data are consistent with proposed genetic factors controlling male crossing over in the tester stocks and to the presence of enhancers and suppressors of male crossing over segregating in the Brazilian populations (1986).

Key words: isofemale lines, natural populations, genetic recombination, genetic variability, male crossing over. 


\section{Introduction}

The higher Diptera generally shows no recombination in males, although a low spontaneous frequency is reported for several species, e.g. Musca domestica (for review see Gethmann 1988). In Lucilia cuprina and Ceratitis capitata, crossing over occurs in males at low frequency and associated with translocations (for review see Gethmann 1988 and Ashburner et al. 2005). In Drosophilidae, meiotic recombination in males is rare (Morgan 1912, 1914). Both male recombination and neo-sex chromosomes cooccurs in a drosophilid fly, Scaptodrosophila hibisci, suggesting that male recombination may be a primitive condition retained in this species, and related to chromosome rearrangements resulting in homologue heterozygosity and to possible translocation chains observed in meiosis (Wilson et al. 2006). Spontaneous male recombination is known in a number of Drosophila species, including D. ananassae (Kikkawa 1937, Moriwaki 1937), D. bipectinata (Singh and Banerjee 1996), D. simulans (Woodruff and Bortolozzi 1976), D. melanogaster (Hiraizumi 1971), D. virilis (Kikkawa 1933, 1935) and D. willistoni (Franca et al. 1968). The recombinants in some of these species were characterized as being related to mitotic exchanges in the male gonial cells or to meiotic exchange in diplotene of spermatocytes. In D. melanogaster, male recombination was recognized as being a component of the PM dysgenic syndrome by Kidwell et al. (1977). The frequency for each major autosomes is of the order of $1-2 \%$ of the total of control males, non dysgenic males. The frequency of mitotic recombinants in the male germ line of dysgenic hybrids is correlated to the gonadal dysgenesis (for review see Ashburner et al. 2005). Franca et al. (1968) reported male recombination between two non-overlapping inversions in chromosome 2 in $D$. willistoni. The frequency of recombination was low, 04\%, without indication of clusters 
of recombinants. Cytological evidence of male meiotic crossing over in this species was evidenced by the presence of a chiasma inside the distal inversion on chromosome IIL in a diplotene cell of male larva (dos Santos-Colares et al. 2004).

D. ananassae is the only species of Drosophila characterized with a considerable frequency of spontaneous crossing over. The occurrence of regular exchange in males of this species was independently discovered by Kikkawa (1937) and Moriwaki (1937). Since 1960 , crossing over in males of $D$. ananassae has been recurrently rediscovered, e.g. Mukherjee (1961), Moriwaki and Tobari (1967, 1968) and Hinton (1970). The frequency of male exchange varies greatly between strains, depending on the genetic background (Hinton 1970; Moriwaki et al. 1979). It is usually considerably less that in females, although some strains are known in which the frequency of male and female exchanges, between a given pair of markers, can almost be the same (Sato et al. 2000).

The genetic basis of male recombination is complex, involving both suppressor and enhancer alleles, as well as cytoplasmic factors (reviewed by Matsuda et al. 1993). Both Kikkawa (1937) and Moriwaki (1940) reported that recombination in males of $D$. ananassae is controlled by chromosomal dominant enhancer genes, $E n(s)$ in chromosome 3 and En-II in chromosome 2. Since then, genetic elements controlling male crossing over have been mapped on chromosomes 2 and 3 (Hinton 1970; Matsuda and Tobari 1983). In all these studies, male crossing over was demonstrated using $\mathrm{F}_{1}$ individuals from crosses between wild type strains and marker stocks.

The mechanism of male crossing over in D. ananassae is meiotic. This was confirmed by genetic analysis, that is, equality of complementary crossover classes and an absence of clusters of recombinants (Kale 1969; Moriwaki and Tobari 1975). Hinton and Downs (1975) reported chiasmata in meiotic prophase of spermatocytes, although 
they failed to detect any correlation between meiotic chromosome behavior and specific genes regulating crossing over in males. Cytological approach of male crossing over was reexamined by Matsuda et al. (1983) demonstrating that chiasmata occur in males at frequencies capable of accounting for the observed recombination values in male hybrids. They also reported that chromosome aberrations observed in diplotene bivalents showed a remarkable parallelism to chiasmata in terms of frequency and distribution. Further cytology analysis of male crossing over in individuals from both marker and wild stocks, and their hybrids was performed by Goñi et al. (2006). The authors reported that cytological exchanges resulted in genetic crossing over, and that chiasma frequency and genetic recombination correlated positively in chromosomes 2 and 3. Notably, scoring of the chiasma demonstrated that males homozygous for previously mapped enhancers of male crossing over, i.e. 3 ple-cy, had low frequencies of chiasmata, whereas higher frequencies of chiasmata were observed in males heterozygous for enhancers, i.e. $e^{65}$ se; bri ru/+ (TNG) (Matsuda et al. 1983, Goñi et al. 2006). The authors concluded that genetic factors controlling male crossing over in $D$. ananassae are involved in the origin of chromosome breakages and exchange events.

These results led the examination of the occurrence of crossing over directly in males living in natural populations (Goñi et al. 2012). Extensive variability in the frequency of chiasmata and chromosome breakages was recorded among wild caught males and in sons of inseminated females from Brazilian populations (data from 1986 and 2007) and two Asian populations, Indonesia and Okinawa (Japan) (data from 2008). Approximately $30 \%(\mathrm{n}=79 / 262)$ of the sampled males presented either chiasma(ta) and (or) isosite chromosome breakage(s) in the first spermatocytes and the frequency of both events were correlated as reported in $F_{1}$ males from several matings between wild 
and marker stocks (Matsuda et al. 1983; Goñi et al. 2006). On the basis of the mean number of observed chiasmata per bivalent, the estimated genetic crossing over in males from natural populations ranged from $1.7 \%$ to $15.0 \%$ per chromosome. These data support for a complex control of male crossing over involved in the origin of chromosome breakages and exchanges acting in natural populations.

In the course of the cytology analysis of wild males from the Brazilian isofemale lines (1986), genetic recombination in $\mathrm{F}_{1}$ males of $D$. ananassae heterozygous for the wild type chromosomes from this population and marker chromosomes from three tester stocks were concurrently performed to search for putative factors controlling male crossing over in this Brazilian populations. The results of this genetic analysis are here presented.

\section{Materials and methods}

\section{Wild isofemale lines}

Flies were collected from domestic habitats such as markets, orchards (decaying fruits), garbage dumps and/or banana traps, in two urban localities in San Pablo State, Brazil, separated by about $250 \mathrm{Km}$ : Rio Claro at inner São Paulo State, and Ubatuba on the Atlantic coast, in June 1986. Isofemale lines were founded from single inseminated females collected in two Brazilian populations, Rio Claro (2 lines) and Ubatuba (21 lines). Analysis of polytene chromosomes of these populations showed to be highly polymorphic for so-called cosmopolitan inversions, $\operatorname{In}(2 L) A, \operatorname{In}(3 L) A$ and $\operatorname{In}(3 R) A$, and

several endemic paracentric inversions on the 2R (Tomimura et. al. 1993, and Tomimura, personal communication), while the $\mathrm{X}$ chromosome carries the standard gene arrangement (for details see Table 2 in Goñi et al. 2012). 


\section{Marker stocks}

Three marker stocks were used as testers for genetic recombination in chromosomes 2 and 3 as described below. For further descriptions of the genetic markers, linkage groups and genetic factors controlling crossing over in males of D. ananassae of these stocks refer to Hinton (1970), Moriwaki and Tobari (1993) and Matsuda et al. (1993).

(1) $e^{65}$ se; bri ru (=ES) stock carries the following recessive mutations: $e^{65}$ (ebony, body color) and se (sepia, eye color) on chromosome 2 and bri (bright, eye color) and $r u$ (roughoid, eye texture) on chromosome 3 (Moriwaki and Tobari 1975). It also carries a dominant suppressor of male crossing-over, $S u(2)-b s$, on $2 \mathrm{~L}$ closely linked to $e^{65}$ mapped in $e^{65}$ Arc se; bri ru stock (Matsuda and Tobari 1983). The $S u(2)-b s$ completely suppressing the effect of most of the enhancers, except En (s)-Tonga (Matsuda and Tobari 1983). The ES stock is structurally homozygous for the standard sequences except for $2 \mathrm{~L}$, which is segregating the standard and the $\operatorname{In}(2 L) A$ sequences.

(2) 3ple-px and (3) 3ple-cy stocks carry the following recessive mutations on the chromosome 3: bri (bright eye color), pe (peach, eye color), stw (straw body, bristle and wing color), $p x$ (plexus wing venation) and $r u$ (rough eye texture), and $c y$ (curly wing posture) markers. However, as pointed out by Hinton (1970) the mutants $p x$ and $c y$ were not reliable markers in that their homozygotes sometimes appeared phenotypically wild, therefore these markers were not scored from the testcrosses of heterozygotes. This author described that the 3ple-px (bri pe stw px ru) marker stock was initially produced through a series of crosses, and when the $c y$ mutant was discovered in a $v$ (vermilion, $\mathrm{X}$ linked) stock, it was transferred to the 3 ple- $p x$, replacing $p x$ to produce the 3 ple-cy (bri pe stw ru cy) stock. Hinton (1970) identified a major dominant enhancer, E(3), of male crossing-over to the right of $r u$ in 3ple-cy, and found it to be associated with the transfer 
of $c y$ from the $v$ stock to the 3ple-px stock, from where it was proposed to have been originated. The $E(3)$ of the 3ple-cy stock is partially suppressed by $S$ (Hinton 1970), and by the $p c$ extrachromosomal suppressor (Hinton 1983). The 3ple-px stock carries no factors known to either enhance or suppress male crossing-over (Hinton 1970). The 3 ple-px and 3ple-cy stocks are homozygous for $\operatorname{In}(2 L) A$ and by the standard sequences of all other arms.

\section{Recombination analysis}

Wild chromosomes from the Brazilian isofemale lines (1986) were sampled in the first or second laboratory generation. This sample method was followed to avoid adaptation to laboratory conditions that may reduce the variance between lines, and/or genetic drift among lines that may produce more and more divergent lines in the course of generations (David et al. 2005). Each isofemale line was tested for male recombination by testcrossing the $F_{1}$ males from mass mating between wild males and marked virgin females of the tester stocks: ES, 3ple-px and 3ple-cy, referred to by the single marker stock involved, producing $F_{1}$ males of three genotypes which were individually assayed for male crossing over in matings to the respective marker females. Three to four $F_{1}$ males from each isofemale line of each genotype were used, and recombination scored among offsprings. Virgin females were separated within $12 \mathrm{hrs}$ after eclosion since they do not mate within $24 \mathrm{hr}$ after eclosion (Tobari and Moriwaki 1993). Experimental crosses were performed routinely by placing into one vial 3 to 4 days old virgins and just emerged single $F_{1}$ male to enhance mating success; and transferred twice to fresh vials after 4 days-egg laying period providing a total of three broods. Progeny counts were taken until 16 days after the parents were placed into a vial. Marker stocks, isofemale lines and experimental crosses were cultured at $25^{\circ}$ on a 
cornmeal, yeast, glucose and agar medium.

Male recombination was monitored between $e^{65} \sim$ se and bri $\sim$ pe in $\mathrm{F}_{1}$ males tested with the ES stock of the second and third chromosomes, respectively, and in the $b r i \sim p e$ $\sim s t w \sim r u$ intervals (regions 1,2 and 3, respectively) of the third chromosome in $\mathrm{F}_{1}$ males tested with the 3ple-px and 3ple-cy stocks. Male recombination value entered in Table 1 was calculated as the sum of all detected exchanges in the chromosomes 2 and 3, regardless of region (in the marked $b r i \sim p e \sim s t w \sim r u$ intervals), divided by the total testcross progeny and expressed as a percentage. Crosses with offspring $\geq 50$ were included in the data. The regional distribution of exchanges in the marked $b r i \sim p e \sim s t w$ $\sim r u$ intervals for selected genotypes is summarized in Table 2 . The genetic distance (female linkage, in $\mathrm{cM}$ ) between the loci used here is as following: $e \sim s e=65$, bri $\sim r u$ $=97.2, b r i \sim p e=7, p e \sim s t w=36$, and $s t w \sim r u=53$.

\section{Data analysis}

Analysis of variance (ANOVA) test was used on individual male recombination data. Previously to the ANOVA analysis, the assumption of normality (KolmogorovSmirnov test) and homogeneity of variance (Levene's test) between males were considered (Zar 2010). Likewise, data were transformed using $\arcsin \sqrt{ } \mathrm{P}$, where $\mathrm{P}=$ percent of recombination. Regression analysis was used to determine the relationship between recombination in the chromosomes 2 and 3 in $F_{1}$ males heterozygous fo ES stock. Data analyses were carried out using PAST version 2.09 (Hammer et al. 2001). For all analysis, the significance level $\mathrm{p}=0.05$ was used.

\section{Results and discussion}

\section{High variability of individual male values of crossing over}


Table 1 shows individual male recombination data recorded for each sampled isofemale and tester stock. In general, mean recombination values in all marked regions were low, although individual male values revealed high variability, depending on the tester considered, as graphically represented in Fig. 1. In all cases, male recombination data were normal and the variances homogeneous $(\mathrm{p}>0.05)$. ANOVA test of individual male recombination value between lines within each tester stock was not significantly different $(p>0.05)$, excepting when data of the 3ple-px and 3ple-cy testers was used ( $p$ $<0.05$ ) (Supplementary Table S1). Data, as details below, support the occurrence of crossing over in males heterozygous for wild chromosomes of the Brazilian isofemale lines (1986) and advocate for a genetic control. Furthermore, males and lines examined here can be considered as representative samples of these populations. The genetic recombination data observed here evidence the proposal of heterogeneity of genetic factors controlling male crossing over segregating in the Brazilian populations (1986).

\section{Enhancer(s) and Suppressor(s) of male crossing over are segregating in the Brazilian populations (1986)}

The presence of Enhancer(s) in the wild chromosomes of the Brazilian populations (1986) could be responsible for the low, but not negligible, recombination values observed in the $F_{1}$ males testcrossed with ES females having individual values ranged up to $0.88 \%$ in the $e^{65} \sim$ se interval, and $4.42 \%$ in the bri $\sim r u$ interval (Table 1, Fig. 1). These Enhancer(s) are not completely suppressed by the $S u(2)$-bs of ES stock, reported as a strong suppressor of male crossing over which suppresses the effect of most enhancers, excepting the En (s)Tonga (Matsuda and Tobari 1983). About 41\% (n=29) of the $F_{1}$ males heterozygous for ES produced recombination (Fig. 1), thus it was determined whether the occurrence of recombination on the chromosome 2 and 3 
marker regions are related. The correlation obtained, $r=0.206, \mathrm{df}=68, \mathrm{p}=0.09$, was not significant at $5 \%$ level suggesting that crossing over in these chromosomes is under independent genetic control.

Variation in the mean recombination values was observed for $F_{1}$ males testcrossed with 3 ple-px and 3ple-cy females (Table 1). High number of $F_{1}$ males of the 3 ple-cy tester $(60 \%, \mathrm{n}=39)$ yielded recombinant progeny, with a maximum value for the bri $p e \sim s t w \sim r u$ sum of intervals of $15.2 \%$, while in $\mathrm{F}_{1}$ males of the 3ple-px tester it was lower $(45 \%, n=32)$, with a maximum value of $19.64 \%$ (Table 1, Fig. 1). Considering the presence of a dominant enhancer, $E(3)$, in the 3 ple-cy stock it is expected that recombination performances between lines in the $\mathrm{F}_{1}$ males of 3 ple- $p x$ and ple-cy testers may differ, as statistically determined ( $\mathrm{p}<5 \%$ level) (Supplementary Table S1). In view that male recombination was completely suppressed in more that $40 \%$ in $\mathrm{F}_{1}$ males of 3 ple-cy tester (Table 1, Fig. 1), it is assumed that dominant Suppressor(s) of crossing over are segregating in the Brazilian populations (1986). On other hand, the presence of male recombination in $\mathrm{F}_{1}$ males of the 3ple-px tester suggests the action of Enhancer(s) of crossing over segregating in the Brazilian populations (1986), since this marker stock carries no factors known to either enhance or suppress male crossing-over (Hinton 1970).

From the first reports on male recombination by Kikkawa (1937) and Moriwaki (1937) using marker stocks, a dominant gene, En-2 located in the second chromosome (Moriwaki 1940) and $E n(s)$ located in the third chromosome (Kikkawa 1938) were proposed to affect crossover frequencies in the chromosome which they were located. Large variation on male recombination frequencies were observed on survey of stocks derived from natural populations (Hinton 1970), wild type from laboratory and inbred 
lines (Moriwaki et al. 1970), isofemale lines derived from several Asian populations (Moriwaki and Tobari 1973), and wild type stocks derived from Indian populations (Mukherjee 1961, Kale 1968).

Moriwaki et al. (1970) reported that about $65 \%$ of chromosomes from laboratory stocks of D. ananassae originated from various localities (Tonga and Hawaii) showed spontaneous male crossing over, proposing some genetic control on both second and third chromosomes. Moriwaki and Tobari (1973) detected male crossing over in 133 wild chromosomes (95\%) of 140 chromosomes tested from isofemale lines established from single inseminated females collected in nature from Taiwan, Borneo, Malaysia, Thailand, Calcutta and Colombo (Sri Lanka). They reported that most of the lines of these localities showed great variation in recombination value between $b \sim$ se loci on chromosome 2 , from 0 to about $20 \%$, with a mean recombination value of $4.0 \%(48.8 \%$ female linkage, in $\mathrm{cM}$ ). When recombination values were examined by analysis of variance, significant differences among lines but not amid localities were observed.

Hinton (1970) used wild chromosomes derived from seven populations from islands of the Pacific Ocean and one in Yucatan, Mexico and the markers stocks, 3ple-px and 3 ple-cy, to test for male recombination, the same marker stocks used here. Individual males having high frequency of recombination in the 3ple-px series suggested the existence of $E$ in the Niue and possibly the dark Tutuila, Majuro, and Hawaii stocks, whereas all eight of the $+/ 3$ ple-cy tests provided evidence for segregation of $S$ in these (wild) stocks. According to Hinton (1970), if $\mathrm{F}_{1}+/ 3$ ple-px males carried both $S$ and $E$, the presence of $E$ would not have been detected, but due to independent segregation of $E$ it would be manifested in one-half of the $\mathrm{F}_{1}$ males. Eighteen $\mathrm{F}_{1}$ males from each of the Truk, Rarotonga, and Palmyra 3ple-px tests yielded maximum individual 
recombination frequencies of $0.01(10 \%)$, thereby failing to demonstrate the presence of $E$ in any of these three stocks. As shown here, about one half of the $\mathrm{F}_{1}$ males of 3 ple-px tester yielded recombinant progeny supporting the segregation of Enhancer(s) in the Brazilian populations (1986) (Table 1). Furthermore, our data supports for independent control of male crossing over in chromosomes 2 and 3 in $F_{1}$ males of ES tester, supporting for an autosomal location of Enhancer(s) of male crossing over segregating in the wild chromosomes 2 and 3 from the Brazilian populations (1986).

\section{Regional distribution of crossing over is genotype dependent}

Variation in recombination values observed in $\mathrm{F}_{1}$ males testcrossed to 3 ple-px and to 3 ple-cy stocks was accompanied by marked differences in the distribution of crossovers among the three marked regions of the third chromosome (Table 2). In general, there is a rough proportionality between the regional distributions of exchanges of the marker regions in both male genotypes respect to the female map length. In these males, crossovers in region 1 were distinctly rare, while for regions 2 and 3 there were considerable variation in their relative crossover frequencies as shown by the R2:R3 ratios $(0.21$ and 0.04$)$ in $+/ 3$ ple- $p x$ and $+/ 3$ ple-cy males, respectively. Our results differ from the data on the regional distribution of exchanges in $\mathrm{F}_{1}$ males $3 p l e p x$ and 3ple cy marked stocks reported by Hinton $(1970,1983)$. High R2:R3 ratios (ranging from 0.61 to 1.45$)$ were observed in $F_{1}$ males heterozygous for 3 ple-cy and $p x$ or $p c$ marker stocks, and interpreted as due to undefined factors in addition to the enhancers identified in the 3ple-cy and $p c$ chromosomes (Hinton 1983). We agree with Hinton (1970, 1983) that data on the regional variation in the distribution of male crossing over shown here are independent of the mean recombination value.

Two hypotesis are proposed to explain the marked difference in the regional 
distribution of exchanges in the $\mathrm{F}_{1}$ males $+/ 3$ ple- $p x$ and $+/ 3$ ple-cy (Table 2). First, the high $\mathrm{R} 2: \mathrm{R} 3$ ratio in $\mathrm{F}_{1}$ males $+/ 3$ ple-px may be related to Enhancer(s) segregating in the wild chromosomes from the Brazilian populations (1986). Second, and not necessarily excluding the previous proposal, the dominant enhancer, $E(3)$, identified in the 3 ple-cy could increase localized crossing over in regions of chromosome 3 with high inversion polymorphim, lowering almost three fold the mean recombinaton value in the $p e \sim s t w$ region. The two types of $F_{1}$ male genotypes examined here are expected to be polymorphic for $\operatorname{In}(2 L) A$ and $\operatorname{In}(2 R) M, N, O$ and $\operatorname{In}(3 L) A$, and specially the cosmopolitan $\operatorname{In}(3 R) A$, as these inversions segregate from the wild chromosomes of the Brazilian populations (1986) (Goñi et al. 2012). The small proximal $\operatorname{In}(3 R) A$, when heterozygous, reduce recombination only in the $s t w \sim p x$ region indicating that the $p x$, $r u$ and $c y$ markers are in 3R (Hinton, 1970). Since inversions have been associated with the supression of crossing over, the occurrence of high frequency of localized crossing over within a paracentric inversion loop, would result in a lower recombinant frequency in the inverted region. Crossing over within inversion loop was demonstrated cytologically in $F_{1}$ males with high recombination value (Matsuda et al. 1983, Goñi et al. 2006) and in wild males from natural populations (Goñi et al. 2012). The genetic consequence of a crossover event, which normally generates the recombinant class of meiotic products, produces instead lethal products. Enhancement of localized crossovers in the pe $\sim s t w$ in $\mathrm{F}_{1}$ males of $+/ 3 \mathrm{px}-c y$ test coupled with $\operatorname{In}(3 R) A$ heterozygous could produce fewer recombinants in this region, resulting in a low $\mathrm{R} 2$ : $\mathrm{R} 3$ ratio.

Our data are consistent with the proposed genetic factors controlling male crossing over in the marker stocks, and provides support for the heterogeneity of factors controlling male recombination, $E n$ and $S u$, segregating in the Brazilian populations 
(1986). The presence of factors controlling male crossing over in D. ananassae, enhancers $(E n)$, suppressors $(S u)$ and additional modifiers of crossing over diagnosed in marker stocks, and characterized in some wild stocks derived from natural populations (see Matsuda et al. 1994), are expected to be widely distributed and maintained in natural populations. The mechanism through which the putative enhancers $(E n)$ and suppressors $(\mathrm{Su})$ operate and the function of meiotic exchange and breakages observed in natural population of D. ananassae remains to be elucidated.

\section{Acknowledgements}

Genetic data was included in the Ph.D. thesis of B.G., Tokyo Metropolitan University, 1989. This study was possible thanks to the courtesy of Dr. Claude W. Hinton for sending us chromosome 3 marker stocks. We are indebted to Dr. Alejo Mesa (deceased) UNESP- Rio Claro, for his assistance during the field study in Brazil. The authors are grateful to Walter Norbis (FREP, Facultad de Ciencias, Universidad de la República, UdelaR, Uruguay) for his advice on statistical analysis of the data; to Dr. Carlos R. Vilela (USP, Brazil) for laboratory facilities while preparing this manuscript, and anonymous reviewers for their valuable suggestions. We thank Fernando Luces for the English correction. This study was partly financed by the Japanese government (Monbukagakusho), and the Uruguayan Institutions: Comisión Sectorial de Investigación Científica (CSIC), Universidad de la República, and Programa de Desarrollo de las Ciencias Básicas (PEDECIBA), Universidad de la República Ministerio de Educación y Cultura, to B.G.

\section{References}

Ashburner, M., Golic, K.G., and Hawley, R.S. 2005. Drosophila: a laboratory handbook. 
Cold Spring Harbor Laboratory Press, New York.

David, J.R., Gibert, P., Legout, H., Pétavy, G., Capy, P., and Moreteau, B. 2005. Isofemale lines in Drosophila: an empirical approach to quantitative trait analysis in natural populations. Heredity, 94(1): 3-12. doi:10.1038/sj.hdy.6800562.

dos Santos-Colares, M.C., Degrand, T.H., and Valente, V.L.S. 2004. Cytological detection of male recombination in Drosophila willistoni. Cytologia (Tokyo), 69(4): 359-365. doi:10.1508/cytologia.69.359.

Franca, Z.M., da Cunha, A.B., and Garrido, M.C. 1968. Recombination in Drosophila willistoni. Heredity, 23(2): 199-204. doi:10.1038/hdy.1968.28. PMID:5245954.

Gerthmann, R.C. 1988. Crossing over in males of higher diptera (Brachycera). J. Hered. 79 (5): 344-350.

Goñi, B., Matsuda, M.,Yamamoto, M.T., Vilela, C.R., and Tobari, Y.N. 2012. Crossing over does occur in males of Drosophila ananassae from natural populations. Genome, 55(7): 505-511. doi:10.1139/g2012-037. PMID:22788379.

Goñi, B., Matsuda, M., and Tobari, Y.N. 2006. Chiasmata and chromosome breakages are related to crossing over in Drosophila ananassae males. Genome, 49(11): 13741383. doi:10.1139/G06-106. PMID:17426752.

Hammer, Ø., Harper, D.A.T., and Ryan, P.D. 2001. PAST: Paleontological Statistics Software Package for Education and Data Analysis. Paleontol. Electron. 4(1): 9pp. Available from http://palaeo-electronica.org/2001_1/past/issue1_01.htm [accessed: 11 March 2013]. 
Hinton, C.W. 1970. Identification of two loci controlling crossing over in males of Drosophila ananassae. Genetics, 66(4): 663-676. PMID:5519661.

Hinton, C.W. 1983. Relations between factors controlling crossing over and mutability in males of Drosophila ananassae. Genetics, 104(1): 95-112. PMID:17246134.

Hinton, C.W., and Downs, J.E. 1975. The mitotic, polytene, and meiotic chromosomes of Drosophila ananassae. J. Hered. 66(6): 353-361. PMID:1219059.

Hiraizumi, Y. 1971. Spontaneous recombination in Drosophila melanogaster males. Proc. Natl. Acad. Sci. U.S.A. 68(2): 268-270. PMID:5277066.

Kale, P.G. 1968. Spontaneous crossing over in males of Drosophila ananassae: Twoway selection for recombination values. Japan. J. Genetics 43(1): 27-31. doi:10.1266/jjg.43.27.

Kale, P.G. 1969. The meiotic origin of spontaneous crossovers in Drosophila ananassae males. Genetics, 62(1): 123-133. PMID:5371009.

Kidwell, M.G., Kidwell, J.F. and Sved, J.A. 1977. Hybrid dysgenesis in Drosophila melanogaster: a syndrome of aberrant traits including mutation, sterility, and male recombination. Genetics, 86(4): 813-833. PMID:17248751.

Kikkawa, H. 1933. Crossing over in the males of Drosophila virilis. Proceedings of the Imperial Academy of Tokyo 9(9): 535-536.

Kikkawa, H. 1935. Crossing over in the male Drosophila virilis. Cytologia, 6(2-3): 190194. doi:10.1508/cytologia.6.190.

Kikkawa, H. 1937. Spontaneous crossing-over in the male of Drosophila ananassae. 
Zoological Magazine, 49: 159-160.

Kikkawa, H. 1938. Studies on the genetics and cytology of Drosophila ananassae. Genetica, 20(5): 458-516. doi:10.1007/BF01531779.

Matsuda, M, and Tobari, Y.N. 1983. Enhancer and suppressor system of male recombination in Drosophila ananassae. Japan. J. Genetics 58(3): 181-191. doi:10.1266/jjg.58.181.

Matsuda, M., Sato, H., and Tobari, Y.N. 1993. Crossing over in males. In Drosophila ananassae. Genetical and Biological Aspects. Edited by Y.N. Tobari. Japan Scientific Societies Press and Karger, Tokyo, and Basel. pp. 53-72.

Morgan, T.H. 1912. Complete linkage in the second chromosome of the male of Drosophila. Science, 36(934): 719-720. doi:10.1126/science.36.934.719.

Morgan, T.H. 1914. No crossing over in the male of Drosophila of genes in the second and third pairs of chromosomes. Biol. Bull. 26(4): 195-204.

Moriwaki, D. 1937. A high ratio of crossing-over in Drosophla ananassae. Z. Indukt. Abstamm.-Vererbunsl. 74(1): 17-23.

Moriwaki, D. 1940. Enhanced crossing over in the second chromosome of Drosophila ananassae. Japan. J. Genetics 16(2):37-48. doi:10.1266/jjg.16.37.

Moriwaki, D., and Tobari, Y.N. 1967. Male crossing over in Drosophila ananassae. Dros. Inf. Serv. 42: 81.

Moriwaki, D., and Tobari, Y.N. 1968. Unusual segregation of the four phenotypes in the dihybrid $\mathrm{F}_{2}$ generation caused by male crossing in Drosophila ananassae. Dros. Inf. 
Serv. 43: 134-135.

Moriwaki, D., and Tobari, Y.N. 1973. Spontaneous male crossing-over of frequent occurrence in Drosophila ananassae from Southeast Asian populations. Japan. J. Genetics 48(3): 167-173. doi:10.1266/jjg.48.167.

Moriwaki, D., and Tobari, Y.N. 1975. Drosophila ananassae. In Handbook of genetics, vol 3. Edited by R.C. King. Plenum, New York. pp. 513-535.

Moriwaki, D., Tobari, Y.N., and Oguma, Y. 1970. Spontaneous crossing-over in the male of Drosophila ananassae. Japan. J. Genetics 45(5): 411-420. doi.org/10.1266/jjg.45.411.

Moriwaki, D., Tobari, Y.N., and Matsuda, M. 1979. The role of Y chromosome in male crossing over in Drosophila ananassae. Japan. J. Genetics 54(4): 295-302. doi.org/10.1266/jjg.54.295.

Moriwaki, D., and Tobari, Y.N. 1993. Catalog of mutants. In Drosophila ananassae. Genetical and Biological Aspects. Edited by Y.N. Tobari. Japan Scientific Societies Press and Karger, Tokyo, Basel. pp. 209-259.

Mukherjee, A.S. 1961. The effect of selection on crossing over in the males of Drosophila ananassae. Amer. Naturalist 95(880): 57-59.

Sato, H., Goñi B., Matsuda, M., and Tobari, Y.N. 2000. A site specific increase in recombination in Drosophila ananassae. Genes Genet. Syst. 75(1): 41-47. doi:10.1266/ggs.75.41

Singh, B.N., and Banerjee, R. 1996. Spontaneous recombination in males of Drosophila 
bipectinata. J. Biosci. 21(6): 775-779. doi:10.1007/BF02704718.

Tobari, Y.N., and Moriwaki, D. 1993. Life cycle. In Drosophila ananassae. Genetical and Biological Aspects. Edited by Y.N. Tobari. Japan Scientific Societies Press and Karger, Tokyo, Basel. pp. 1-5.

Tomimura, Y., Matsuda, M., and Tobari, Y.N. 1993. Population Genetics: Polytene chromosome variations of Drosophila ananassae and its relatives. In Drosophila ananassae. Genetical and Biological Aspects. Edited by Y.N. Tobari. Japan Scientific Societies Press and Karger, Tokyo, Basel. pp. 139-151.

Wilson, A.C.C., Sunnucks, P., Bedo, D.G., and Baker, J.S.F. 2006. Microsatellites reveal male recombination and neo-sex chromosome formation in Scaptodrosophila hibisci (Drosophilidae). Genet. Res. 87(1): 33-43. doi:10.1017/S0016672306007968.

Woodruff, R.C., and Bortolozzi, J. 1976. Spontaneous recombination in males of Drosophila simulans. Heredity 37(2): 295-298. doi:10.1038/hdy.1976.90.

Zar, J.H. 2010. Biostatistical analysis. Prentice Hall. 
Table 1. Male recombination assayed in the Brazilian populations (1986) of Drosophila ananassae.

\begin{tabular}{|c|c|c|c|c|c|c|c|c|c|c|}
\hline \multirow{3}{*}{$\begin{array}{l}\text { Isofemale } \\
\text { lines' } \\
\text { code }^{a} \\
(n=23)\end{array}$} & \multicolumn{10}{|c|}{ Genotypes of testcrossed $F_{1}$ males ${ }^{b}$} \\
\hline & \multicolumn{4}{|c|}{ +/e se; +/bri ru } & \multicolumn{3}{|c|}{$+/ 3$ ple- $p x$} & \multicolumn{3}{|c|}{$+/ 3$ ple-cy } \\
\hline & $\begin{array}{l}\text { No. of } \\
\text { males }\end{array}$ & $e \sim s e$ & $b r i \sim r u$ & $\begin{array}{l}\text { Total } \\
\text { progeny }\end{array}$ & $\begin{array}{l}\text { No. of } \\
\text { males }\end{array}$ & $\begin{array}{l}\text { Sum of intervals: } \\
b r i \sim p e \sim s t w \sim r u\end{array}$ & $\begin{array}{l}\text { Total } \\
\text { progeny }\end{array}$ & $\begin{array}{l}\text { No. of } \\
\text { males }\end{array}$ & $\begin{array}{l}\text { Sum of intervals: } \\
b r i \sim p e \sim s t w \sim r u\end{array}$ & $\begin{array}{l}\text { Total } \\
\text { progeny }\end{array}$ \\
\hline 55 & 3 & $0,0,0$ & $0,0,0$ & 274 & 3 & $0,0,0.51$ & 698 & 3 & $0,0,2.55$ & 573 \\
\hline 59 & 2 & 0,0 & 0,0 & 135 & 4 & $\begin{array}{l}0.42,1.66,2.00, \\
2.63\end{array}$ & 644 & 4 & $0,0,0,0$ & 624 \\
\hline 79 & 3 & $0,0,0$ & $0,0.48,1.48$ & 501 & 3 & $0,0.74,5.21$ & 682 & 3 & $1.14,8.90,9.68$ & 446 \\
\hline 83 & 2 & 0,0 & 0,0 & 355 & 5 & $0,0,0,0,0$ & 783 & 2 & $0,4.81$ & 288 \\
\hline 84 & 5 & $0,0,0,0,0$ & $0,0,0,0,0$ & 523 & 3 & $0,0.43,8.80$ & 467 & 3 & $0,4.76,11.29$ & 360 \\
\hline 91 & 3 & $0,0,0$ & $0,0,1.42$ & 517 & 3 & $0,0,5.52$ & 461 & 3 & $0,0,1.85$ & 330 \\
\hline 93 & 3 & $0,0,0.87$ & $0,0.53,0.43$ & 754 & 3 & $0.39,0.40,1.33$ & 805 & 3 & $5.07,11.63,14.71$ & 403 \\
\hline 99 & 2 & 0,0 & $0,0.34$ & 560 & 3 & $0,0.56,2.36$ & 476 & 3 & $2.35,4.81,15.00$ & 628 \\
\hline 102 & 3 & $0,0,0$ & $0,0,0$ & 391 & 3 & $0,1.65,2.63$ & 503 & 4 & $0,0,0,0$ & 496 \\
\hline 104 & 3 & $0.29,0.43,0.77$ & $1.46,0.43,0.77$ & 704 & 2 & $0.69,1.30$ & 298 & 2 & $2.07,3.55$ & 342 \\
\hline 116 & 3 & $0,0,0.37$ & $0,0,0$ & 550 & 3 & $0,0,1.40$ & 791 & 2 & $1.94,2.09$ & 346 \\
\hline 117 & 3 & $0,0,0.41$ & $0,0.38,0$ & 715 & 3 & $0,2.77,19.90$ & 706 & 3 & $0,4.27,4.80$ & 318 \\
\hline 118 & 3 & $0,0,0$ & $0,0.63,2.15$ & 895 & 3 & $0,0,0$ & 578 & 2 & $0,8.33$ & 311 \\
\hline 119 & 2 & 0,0 & 0,0 & 335 & 4 & $0,0,0,0$ & 586 & 2 & $0,4.27$ & 267 \\
\hline
\end{tabular}




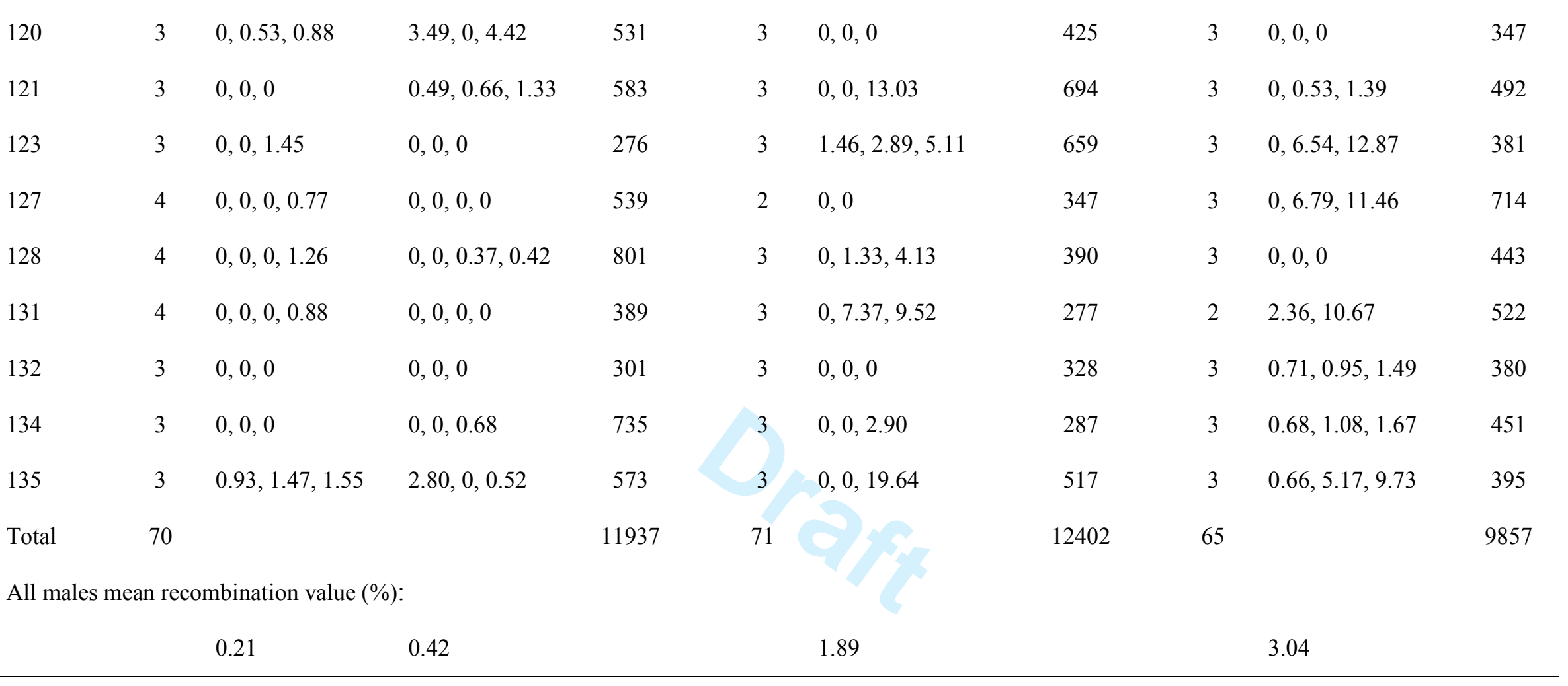

Note: Individual male recombination data for the $e \sim s e$ and $b r i \sim r u$ marker regions are shown sequentially in each isofemale line.

${ }^{a}$ Populations: Río Claro (lines 55 and 59) and Ubatuba (all other lines).

${ }^{\mathrm{b}}$ Female contribution to the right. 
Table 2. Regional distribution of crossovers, with ratios $(R 2: R 3)$ and coincidences $\left(\mathrm{C}_{2,3}\right)$ of crossovers in regions 2 and 3 , in testcross progenies of $F_{1}$ males from the Brazilian populations (1986).

\begin{tabular}{|c|c|c|}
\hline \multirow[b]{2}{*}{$\begin{array}{l}\text { Testcross } \\
\text { Progeny }\end{array}$} & \multicolumn{2}{|c|}{$\begin{array}{l}\text { Genotypes of testcrossed } \\
F_{1} \text { males }\end{array}$} \\
\hline & $+/ 3$ ple- $p x$ & $+/ 3$ ple-cy \\
\hline $\mathrm{NCO}$ & 12171 & 9557 \\
\hline $\mathrm{SCO} 1(b r i \sim p e)$ & 2 & 2 \\
\hline $\mathrm{SCO} 2(p e \sim s t w)$ & 36 & 11 \\
\hline $\operatorname{SCO} 3(s t w \sim r u)$ & 189 & 287 \\
\hline $\operatorname{DCO} 2,3$ & 4 & 0 \\
\hline Total & 12402 & 9857 \\
\hline Region 1 (bri pe) & 0.02 & 0.02 \\
\hline Region $2(p e \sim s t w)$ & 0.32 & 0.11 \\
\hline Region $3(s t w \sim r u)$ & 1.56 & 2.91 \\
\hline Total & 1.89 & 3.04 \\
\hline $\mathrm{R} 2: \mathrm{R} 3$ & 0.21 & 0.04 \\
\hline $\mathrm{C}_{2,3}$ & $4 / 0.62$ & 0 \\
\hline
\end{tabular}




\section{Figure caption}

Figure 1. Distribution of percent recombination values in males of Drosophila

ananassae heterozygous for wild type chromosomes of Brazilian populations (1986)

and chromosomes from three marker stocks. 

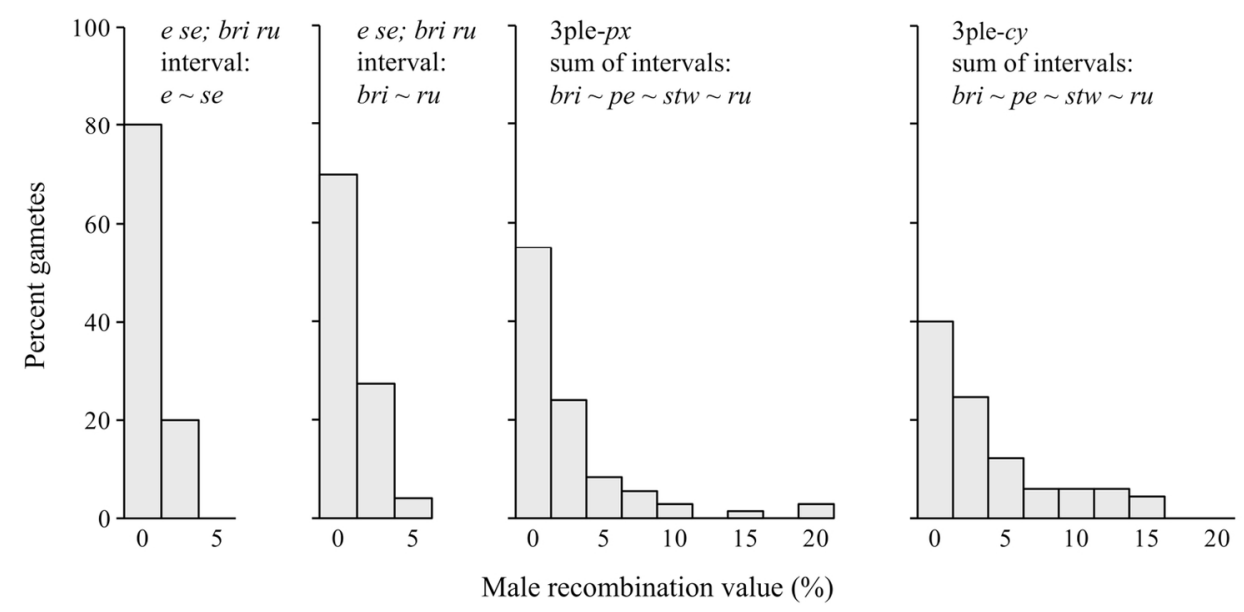

$70 \times 33 \mathrm{~mm}(600 \times 600 \mathrm{DPI})$ 
Supplementary Table S1. Results of ANOVA on the data shown in Table 1.

\begin{tabular}{|c|c|c|c|c|c|}
\hline Tester & Source of variation & $\mathrm{df}$ & MS & $\mathrm{F}$ & $\mathrm{p}$ \\
\hline ese; bri ru & Between lines & 9 & 0.208 & 1.270 & NS \\
\hline \multirow[t]{2}{*}{ Interval: $e \sim s e$} & Within lines & 23 & 0.164 & & \\
\hline & Levene's test: $p=0.998>0.05$ & & & & \\
\hline e se; bri ru & Between lines & 11 & 0.193 & 0.819 & NS \\
\hline \multirow[t]{2}{*}{ Interval: $b r i \sim r u$} & Within lines & 24 & 0.236 & & \\
\hline & Levene's test: $p=0.985>0.05$ & & & & \\
\hline 3ple-px & Between lines & 16 & 0.261 & 0.434 & NS \\
\hline Sum of intervals: & Within lines & 34 & 0.601 & & \\
\hline$b r i \sim p e \sim s t w \sim r u$ & Levene's test: $p=0.995>0.05$ & & & & \\
\hline 3ple-cy & Between lines & 19 & 0.765 & 1.849 & NS \\
\hline Sum of intervals: & Within lines & 36 & 0.414 & & \\
\hline$b r i \sim p e \sim s t w \sim r u$ & Levene's test: $p=0.831>0.05$ & & & & \\
\hline 3 ple- $p x$ and 3ple-cy & Between lines & 21 & 0.834 & 1.684 & $0.044 *$ \\
\hline Sum of intervals: & Within lines & 108 & 0.495 & & \\
\hline$b r i \sim p e \sim s t w \sim r u$ & Levene's test: $p=0.9803>0.05$ & & & & \\
\hline
\end{tabular}

df: degree of freedom; MS: mean square; F: variance ratio; NS: nonsignificant at 5\% level;

$* \mathrm{p}<0.05$. 